it is, in effect, an instantaneous measure. We also disagree that the airborne fraction is an inappropriate parameter: given the current structure of emissions among industrial and developed countries, there is unfortunately virtually no likelihood of stabilizing — let alone reducing atmospheric concentrations for any major greenhouse gas in the next $20-25$ years.

ALLEN L. HAMMOND ERIC RODENBURG

World Resources Institute,

1709 New York Avenue NW,

Washington, DC 20006, USA

WiLLIAM MOOMAW

Center for Environmental Management,

Tufts University,

Medford, Massachusetts 02155, USA

1. Hammond, A. L., Rodenburg, E. \& Moomaw, W. Nature 347, 705-706 (1990)

2. Houghton, J. T., Jenkins, G. J. \& Ephraums, J. J. (eds) Climate Change - The IPCC Scientific Assessment (Cambridge University Press, 1990)

3. Lashof, D. A. \& Ahuja, D. R. Nature 344, 529-531 (1990)

3. Lashof, D. A. \& Ahuja, D. R. Nature 344, 529-531 (1990).
4. Maier-Reimer, E. \& Hasselmann, K. Clim. Dyn. 2, 63-90 (1987).

5. Victor. D. Nature 347, 431 (1990)

\section{Testing times}

SIR-Although I do not dispute the general case made by Blinkhorn and Johnson' against the spurious uses to which personality testing is all too often put in the business world, let us not condemn the good along with the bad. The chief abuse which Blinkhorn and Johnson rightly castigate lies in the simultaneous application of large numbers of scales to small samples of people, followed by statistically unsound interpretation of the many coefficients of correlation with performance indices thus obtained.

But there is another, sounder, tradition in scientific research on personality which can yield useful practical, including business, applications. I refer to studies (and there is a substantial corpus of them) in which fewer, broader and statistically independent personality traits, or dimensions", have been shown to correlate reliably with experimental measures of behaviour in ways predicted by relevant theory. To give just two examples: if a job requires prolonged perceptual vigilance under boring circumstances (such as proof-reading), it is better (other things being equal) to choose someone of introverted personality': and if it requires persistence in spite of repeated rejection (such as selling insurance), you would do well to pick people with an optimistic attributional style:

Before your readers accept too readily Blinkhorn and Johnson's overly pessimistic conclusion that there is "precious little evidence that even the best personality tests predict job performance", they should read at least the second of these reports. This demonstrates a highly successful application of personality testing in the US insurance industry", with results that we, in an as-yet-unpublished study, have been able substantially to replicate in the UK.

Department of Psychology,

JefFrey A. GRAY

Institute of Psychiatry,

De Crespigny Park,

Denmark Hill,

London SE5 8AF, UK

1. Blinkhorn, S. \& Johnson, C. Nature 348, 671-672 (1990)

2. Eysenck, H. J. (Ed.) A Model For Personality (Springer, New York, 1981)

3. Seligman. M. E. P. \& Schuiman, P. J. Personality soc. Psychol. 50. 832-838 (1987)

SIR - Blinkhorn and Johnson could well be correct in asserting that there is "precious little evidence that even the best personality tests predict job performance". Such a condemnation may however be unjustified.

Astonishingly, the authors make no reference to the context in which the test is used. A very basic lesson in psychometrics is that the 'validity' of a test depends critically on the base rate of the characteristic in the population under test and the selection ratio relating applicants to posts. In the present context, the base rate refers to

Percentage accuracy of a hypothetical 'low validity' test in classifying applicants as suitable or unsuitable

\begin{tabular}{cccc}
\hline & & \multicolumn{3}{c}{ Actual suitability } \\
& & + & - \\
Test classification & + & 25 & 2.5 \\
& - & 75 & 97.5 \\
\hline
\end{tabular}

the percentage of applicants who would actually be suitable; to the extent that this deviates from $50 \%$, the usefulness of any test procedure in reducing selection errors is impaired. The selection ratio refers to the number of applicants for each available position. Where this ratio is high even tests of very low predictive power can make a contribution. As an extreme example, consider the hypothetical test in the table which inappropriately rejects $75 \%$ of suitable applicants. Overall, in classifying a pool of applicants of whom $50 \%$ are suitable it has a $38.75 \%$ error rate - hardly appealing as a valid test.

Consider now the use of this test to appoint 20 individuals from a pool of 160 , of whom only $50 \%$ are actually suitable. Without using the test, and selecting randomly, we would expect $50 \%$ of the appointees to be suitable - a total of only ten. However, using even this "invalid' test can be expected to increase the number of suitable appointees to a little over 18 out of the 20 . Of course a total of 60 suitable applicants have also been unjustly rejected by the test - but one might cynically expect this to be of little concern to the organization. Such arguments can be extended beyond categorical (suitable/ unsuitable) variables to continuous ones, and can of course take account also of the utilities (in a bayesian sense) associated with different outcomes.

R. GLYNN OWENS

Department of Clinical Psychology,

University of Liverpool,

PO Box 147, Liverpool L69 3BX, UK

BLINKHORN AND JOHNSON REPLY - It is certainly the case that even tests with rather low predictive validity may have practical use when selection ratios and/or base rates take on appropriate values. This much has been known since $\mathrm{H}$. C. Taylor and J. J. Russell published their tables in the Journal of Applied Psychology 23, 565-578; 1939.

The validity coefficient is a multiplier in the numerator of the formula for the utility of a selection device. So if validity is zero, the test can have no utility. Owen's table is misleading as an example of low validity, as it corresponds to a (phi) correlation of 0.33 if $50 \%$ of applicants are suitable. This is as high a correlation as is typically claimed for good single tests. Our point is that in most cases test validities are seen to be not significantly different from zero when appropriate standards are applied.

S. BLINKHORN C. JOHNSON

Psychometric Research and

Development Ltd,

Brewmaster House, The Maltings,

St Albans, Herts AL1 BHT, UK

\section{Fertilizer and climate change}

SIR-Mayewski et al. ${ }^{1.2}$ reported a recent rise in nitrate concentration in carcfully dated polar snow deposits (up to 1988), thereby extending our knowledge of the range and degree of global climate chemistry changes in remote environments, and discussed a link between these changes and both the formation of the Antarctic ozone hole and global warming. They suggested that the source of the precursor gaseous nitrogen ultimately deposited as nitrate came from fossil fuel sources. But, as I explain here, fertilizers could also be a source of recently deposited nitrate.

Global nitrogen fertilizer consumption

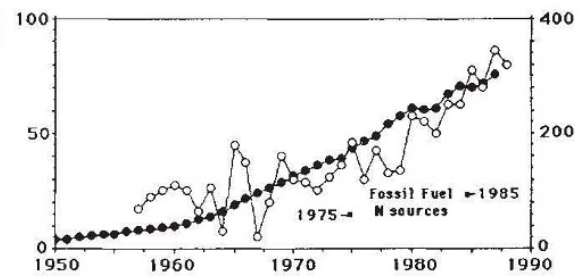

Nitrate concentration $(O$, ng per $g$ ) in snowfall at South Pole station T (Fig. 3 of ref. 1), world nitrogen fertilizer consumption ( million $\mathrm{mt}$ ) and an estimate of atmospheric nitrogen emissions from fossil fuels (-) in 1975 (ref. 5) and 1985 (based on fossil fuel consumption since 1975). 